\section{Paediatric bacterial keratitis cases in Shanghai: microbiological profile, antibiotic susceptibility and visual outcomes}

J Hong ${ }^{1,4}$, J Chen ${ }^{1,4}$, X Sun ${ }^{1,2}$, SX Deng ${ }^{3}$, L Chen', L Gong ${ }^{1}, \mathrm{~W} \mathrm{CaO}^{1}, \mathrm{X} \mathrm{Yu^{1 }}$ and $\mathrm{J} \mathrm{Xu}^{1}$

\begin{abstract}
Purpose The purpose of this study was to review the microbiological profile, in vitro antibiotic susceptibility and visual outcomes of paediatric microbial keratitis in Shanghai, China over the past 6 years.

Methods Medical records of patients aged $\leq 16$ years were reviewed, who were diagnosed as having bacterial keratitis between 1 January 2005 and 31 December 2010. Bacterial culture results and in vitro antibiotic susceptibility were analysed. A logistic regression analysis was conducted to evaluate the relationship between visual impairment and possible risk factors. Results Eighty consecutive cases of paediatric bacterial keratitis cases were included, among which 59 were identified as having positive culture. Staphylococcus epidermidis was the most commonly isolated organism $(n=23 ; 39.0 \%)$, followed by Streptococcus pneumoniae $(n=11 ; 18.6 \%)$ and Pseudomonas aeruginosa $(n=6 ; 10.2 \%)$. Antibiotic sensitivities revealed that tested bacteria had low resistance rates to fluoroquinolones and aminoglycosides

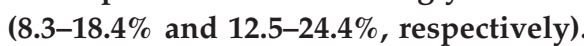
Multivariate logistic regression analysis proved that visual impairment was significantly associated with Gram-negative bacterial infection (odds ratio $(\mathrm{OR})=7.626$; $P=0.043)$ and an increasing number of resistant antibiotics $(\mathrm{OR}=0.385 ; P=0.040)$. Conclusions S. epidermidis was the most common isolated organism in Shanghai paediatric keratitis. The fluoroquinolones and aminoglycosides remained good choices for treating these patients. Gram-negative
\end{abstract}

bacterial infection and an increasing number of resistant antibiotics were associated with worse visual prognoses in paediatric keratitis.

Eye (2012) 26, 1571-1578; doi:10.1038/eye.2012.210; published online 19 October 2012

Keywords: bacterial keratitis; antibiotics; paediatrics; prognosis; susceptibility

\section{Introduction}

Paediatric bacterial keratitis is an uncommon but potentially devastating condition. The disease is particularly grave in children because they are at greater risk of developing irreversible ocular sequelae, most notably secondary amblyopia. ${ }^{1}$ In addition, infectious inflammation in ocular surface appears to be more severe in paediatric patients, and usually they are more difficult in cooperating with ocular examination and topical medication. ${ }^{2}$ Hence, empiric antibiotic treatment may be of utmost importance before culture results are available. However, most therapy regimens for paediatric bacterial keratitis are based on current guidelines for the treatment and management of this disease in adults. ${ }^{3}$ As a result, susceptibility testing should be performed periodically to ensure that the antimicrobials available are providing sufficient coverage against clinical isolates of pathogenic bacteria.

It is worth noting that despite the significant morbidity of paediatric bacterial keratitis, the incidence, pathogenesis, diagnosis, and predisposing factors of the disease in this patient group are not well known. So far, only a
${ }^{1}$ Department of Ophthalmology, Eye, Ear, Nose, and Throat Hospital, School of Shanghai Medicine, Fudan University, Shanghai, China

${ }^{2}$ State Key Laboratory of Medical Neurobiology, Institutes of Brain Science, Shanghai, China

${ }^{3} J u l e s$ Stein Eye Institute, Los Angeles, CA, USA

Correspondence:

J Xu, Department of Ophthalmology, Eye, Ear, Nose and Throat Hospital, School of Shanghai Medicine, Fudan University, 83 Fenyang Road, Shanghai 200031, China

Tel: +86 013816881607 ; Fax: +8602164377151.

E-mail: jianjiangxu@

126.com

${ }^{4}$ These authors contributed equally to this work.

Received: 16 November 2011

Accepted in revised form: 18 June 2012 Published online: 19 October 2012 
few studies from the United States, India, and Taiwan have demonstrated its characteristics, ${ }^{1,4-8}$ with predisposing factors reported to be contact lens wear, trauma, ocular disease, systemic disease, and environmental factors. ${ }^{2,9,10}$ The purpose of this study was to review the microbiological profile and in vitro antibiotic susceptibility of paediatric bacterial keratitis diagnosed by our institution, and to explore their relationships with visual outcomes.

\section{Materials and methods}

\section{Study population}

A retrospective review of the clinical and microbiological records of Shanghai Eye, Ear, Nose, and Throat Hospital, China identified 80 bacterial keratitis cases among children aged $\leq 16$ years from January 2005 to December 2010. The Medical Ethics Committee of our unit approved the study protocol before data collection. The research conducted met the tenets of Helsinki. Written consent was obtained from patients' parents. Patients who met the criteria of having corneal stromal infiltrate on slit-lamp examination and its microbiological evaluation for suspected microbial keratitis were included in this study, as shown in Supplementary Figure 1. Patients who were suspected of having bacterial keratitis based on their clinical findings and had undergone further microbiological evaluation were included in this study. Patients either suspected of having fungal, viral, or acanthamoeba infection based on clinical findings, or having a positive culture of these pathogens were excluded.

\section{Microbiological analysis}

All patients had initial corneal smears and cultures using a previously described technique. ${ }^{1,9}$ Sedation with intramuscular promethazine $(2 \mathrm{mg} / \mathrm{kg})$ was administered if required. Briefly, corneal scrapings obtained by a sterile Bard Parker blade were inoculated directly into a blood, chocolate, non-nutrient, Sabouraud's dextrose agar and potato dextrose agar, thioglycolate, and brain-heart infusion broth.

Sabouraud's and potato dextrose agar plates were incubated at $25^{\circ} \mathrm{C}$ to enhance the growth of fungi, and the remainder was incubated at $37^{\circ} \mathrm{C}$. Blood agar was incubated under both aerobic and anaerobic conditions, chocolate agar was incubated at 5\% carbon dioxide and non-nutrient agar was incubated with an added Escherichia coli suspension. A culture was considered positive when there was growth of the same organism on two or more media, confluent growth at the site of inoculation on one solid medium, growth in one medium with consistent direct microscopic findings or growth of the same organism on repeated corneal scraping. In vitro susceptibility was determined by Kirby-Bauer disk diffusion and E test (AB Biodisk, Piscataway, NJ, USA). Susceptibility testing of bacterial isolates was performed with fluoroquinolones (levofloxacin, ciprofloxacin, and ofloxacin), aminoglycosides (tobramycin, gentamicin, and amikacin), cephalosporins (cefepime, ceftazidime, and cefazolin), penicillin, and vancomycin.

\section{Treatment}

Against bacterial keratitis, levofloxacin $(0.5 \%)$ hourly was the first line of therapy. If clinical response was unsatisfactory, antimicrobial therapy was changed either by adding tobramycin $(0.3 \%)$ or as per culture and antibiotic susceptibility reports, if available. ${ }^{11}$ Patients with any of the following conditions, including extremely thin cornea, impending or frank perforation, progressive or unresponsive disease, and endophthalmitis, underwent keratoplasty to remove the focal infection and restore visual acuity.

\section{Visual outcome evaluation}

The following data were collected from each patient: age, gender, bacterial isolates, number of resistant antibiotics, the duration of the symptoms before the first examination, ocular surface diseases (that is, previous herpetic infection, blepharitis, or other eyelid abnormalities), ocular surgery (corneal, cataract, or vitreous surgery), and ocular trauma. Different visual acuity tests were performed at 3 months after initiation of antibiotic therapy according to patients' age. In infants who were younger than 16 months, Fixation and Following Test was chosen; in toddlers with age between 16 months and 3 years, Hundred and Thousand Sweet Test was used; in those older than 3 years, if data were available, visual outcome was recorded using Snellen letter charts. In the present study, eyes with either negative result of Fixation and Following Test or Hundred and Thousand Sweet Test or best-corrected distance visual acuity worse than 6/60, were considered as visual impairment. Three patients with obvious corneal leukoma were also defined as visually impaired, although their visual acuity was not available.

\section{Statistical analysis}

Statistical analysis was performed using a statistical software package (SPSS for Windows, version 16.0; SPSS, Inc., Chicago, IL, USA). Data are shown as mean \pm SD. For comparison, the data were grouped into two 3-year study periods, from January 2005 to December 2007 and 
from January 2008 to December 2010. The percentage of bacterial isolates was analysed by $\chi^{2}$-test and Fisher's exact test. All variables of patients' data were entered into univariate analysis; variables with a probability of $\leq 0.2$ for relationship with visual outcome were entered into multivariate logistic regression analysis. All $P$ values were two-sided and considered statistically significant when $<0.05$.

\section{Results}

\section{Demographics of patients}

During the study period, 80 reports of paediatric bacterial keratitis with corneal cultures were received. The average age of all subjects was $6.6 \pm 4.4$ years (range, 0.2-16) and all patients were followed up for $\geq 3$ months. A total of 59 bacterial pathogens were isolated from 59 eyes $(73.8 \%)$, with 37 found in males $(62.7 \%)$, and 22 in females $(37.3 \%)$. None of them were visually impaired before the onset of disease, as reported by their parents.

\section{Microbiological characteristics}

The number of corneal cultures obtained and percentage of positive cultures remained relatively consistent between two 3-year study periods, as shown in Table 1. Staphylococcus epidermidis was the most commonly isolated organism $(n=23 ; 39.0 \%)$, followed by Streptococcus pneumoniae $(n=11 ; 18.6 \%)$ and Pseudomonas aeruginosa $(n=6 ; 10.2 \%)$.
Susceptibility testing of bacterial isolates is shown in Table 2. We analysed the effectiveness of commonly used empirical antibiotics in clinics, including fluoroquinolones, aminoglycosides, cephalosporins, penicillin, and vancomycin. More than $80 \%$ of tested Gram-positive isolates were susceptible to levofloxacin, ciprofloxacin, ofloxacin, amikacin, cefepime, ceftazidime, cefazolin, and vancomycin, whereas $<70 \%$ were sensitive to tobramycin, gentamicin, and penicillin. Less than $20 \%$ of Gram-negative isolates were shown to be resistant to various antibiotics except cefazolin and penicillin.

\section{Multivariate logistic regression analysis for potential risk factors associated with visual impairment}

Visual outcome of the affected eye at final follow-up is shown in Table 3, indicating that 35 eyes (59.3\%) were considered to be visually impaired, including three uncooperative patients because of corneal leukoma. The data of these three patients were subjectively adjusted to facilitate multivariate logistic regression. Table 4 shows the clinical characteristics of paediatric bacterial keratitis cases and univariate analysis for their risk factors. As shown in Table 5 and Supplementary Table 1, two variables were finally proved to have significant association with visual impairment: Gram-negative bacterial infection (odds ratio $(\mathrm{OR})=7.626 ; P=0.043$ ) and an increasing number of resistant antibiotics $(\mathrm{OR}=0.385 ; P=0.040)$.

Table 1 Bacterial isolates identified in Shanghai paediatric bacterial keratitis cases

\begin{tabular}{lccc}
\hline Bacterial culture & $\begin{array}{c}2005-2007 \\
\text { of positive cultures) }\end{array}$ & $\begin{array}{c}2008-2010 \\
\text { n (\% of positive cultures) }\end{array}$ & $\begin{array}{c}\text { Total } \\
\text { n (\% of positive culture) }\end{array}$ \\
\hline Gram-positive isolates $^{\text {a }}$ & 23 & 25 & 48 \\
Staphylococcus epidermidis & $11(40.7 \%)$ & $12(37.5 \%)$ & $23(39.0 \%)$ \\
S. aureus & $3(11.1 \%)$ & Not found & $3(5.1 \%)$ \\
S. auricularis & Not found & $2(6.3 \%)$ & $3(5.1 \%)$ \\
S. warneri & $1(3.7 \%)$ & $1(3.1 \%)$ & $2(3.4 \%)$ \\
S. saprophyticus & Not found & $2(6.3 \%)$ & $2(3.4 \%)$ \\
Streptococcus pneumoniae & $5(18.5)$ & $6(18.8 \%)$ & $11(18.6 \%)$ \\
Micrococcus & $1(3.7 \%)$ & Not found & $1(1.7 \%)$ \\
Corynebacterium species & $1(3.7 \%)$ & Not found & $1(1.7 \%)$ \\
Bacillus & $1(3.7 \%)$ & $2(6.3 \%)$ & $3(5.1 \%)$ \\
Gram-negative isolates & & 7 & 11 \\
Pseudomonas aeruginosa & 4 & $4(12.5 \%)$ & $6(10.2 \%)$ \\
Neisseria species & $2(7.4 \%)$ & Not found & $1(1.7 \%)$ \\
Enterobacter species & $1(3.7 \%)$ & $1(3.1 \%)$ & $1(1.7 \%)$ \\
Aeromonas hydrophila group & Not found & Not found & $1(1.7 \%)$ \\
Acinetobacter lwoffii & $1(3.7 \%)$ & $1(3.1 \%)$ & $1(1.7 \%)$ \\
Shigella sonnei & Not found & $1(3.1 \%)$ & $1(1.7 \%)$ \\
Positive cultures & Not found & 32 & 59 \\
Corneal cultures & 27 & 43 & 80 \\
\hline
\end{tabular}

${ }^{a} \chi^{2}$-test and Fisher's exact test were performed to evaluate the proportion of bacterial isolates between two 3-year study periods, $P>0.05$. 
Table 2 Bacterial isolates resistant to each antibiotic tested from bacterial keratitis cases in Shanghai

\begin{tabular}{|c|c|c|c|c|c|c|}
\hline \multirow[t]{2}{*}{ Antibiotic groups } & \multicolumn{2}{|c|}{ Gram-positive bacteria } & \multicolumn{2}{|c|}{ Gram-negative bacteria } & \multicolumn{2}{|c|}{ Total $^{\mathrm{a}}$} \\
\hline & $\mathrm{n}$ & Resistance (\%) & $\mathrm{n}$ & Resistance (\%) & $\mathrm{n}$ & Resistance (\%) \\
\hline \multicolumn{7}{|l|}{ Fluoroquinolones } \\
\hline Levofloxacin & 37 & 10.8 & 11 & 0 & 48 & 8.3 \\
\hline Ciprofloxacin & 38 & 13.2 & 11 & 9.1 & 49 & 10.2 \\
\hline Ofloxacin & 38 & 18.4 & 11 & 18.2 & 49 & 18.4 \\
\hline \multicolumn{7}{|l|}{ Aminoglycosides } \\
\hline Tobramycin & 34 & 23.5 & 11 & 0 & 45 & 17.8 \\
\hline Gentamicin & 34 & 29.4 & 11 & 9.1 & 45 & 24.4 \\
\hline Amikacin & 29 & 13.8 & 11 & 9.1 & 40 & 12.5 \\
\hline \multicolumn{7}{|l|}{ Cephalosporins } \\
\hline Cefepime & 29 & 6.9 & 11 & 9.1 & 40 & 7.5 \\
\hline Ceftazidime & 29 & 6.9 & 11 & 18.2 & 40 & 10.0 \\
\hline Cefazolin & 29 & 13.8 & 11 & 36.4 & 40 & 20.0 \\
\hline Penicillin & 45 & 68.9 & 11 & 90.9 & 56 & 73.2 \\
\hline Vancomycin & 43 & 0 & Not available & Not available & 43 & 0 \\
\hline
\end{tabular}

${ }^{a}$ For each bacteria isolate, only selected antibiotics were tested.

Table 3 Visual outcomes of paediatric bacterial keratitis in Shanghai $($ eyes $=59)$

\begin{tabular}{lcc}
\hline Eyes & Number of cases & $\%$ \\
\hline $\begin{array}{l}\text { Fixation and following test } \\
\text { (age <younger than 16 months) }\end{array}$ & & \\
$\quad$ Positive & 5 & 8.5 \\
Negative & 3 & 5.1 \\
& & \\
Hundred and thousand sweet test & & 5.1 \\
(age between 16 months and 3 years) & & 3.4 \\
$\quad$ Positive & 3 & \\
Negative & 2 & 18.6 \\
& & 27.1 \\
Visual acuity (age >3 years) & 11 & 27.1 \\
6/6-6/18 & 16 & 5.1 \\
6/24-6/60 & 16 & 100 \\
$\quad<6 / 60$ & 3 & \\
Uncooperative & \\
Total & 59 & 40.7 \\
& & 59.3 \\
Visual impairment & & 100 \\
Yes & & \\
No & & \\
Total & 35 & \\
\hline
\end{tabular}

${ }^{a}$ As these three patients had obvious corneal leukoma, they were also defined as having visual impairment.

${ }^{\mathrm{b}}$ Visually impairment was defined as Fixation and Following Test $(-)$ Hundred and Thousand Sweet Test was ( - ), or best-corrected distance visual acuity was $<6 / 60$ at 3 months after initiation of antibiotic therapy.

\section{Discussion}

Bacterial keratitis occurs infrequently in children, who differ from adults in many aspects, including more difficulty in cooperating with examination and treatment, greater inflammation severity and higher risk of amblyopia. Cases of paediatric bacterial keratitis have been reported in children with the age of 1 month and onwards by various authors. ${ }^{12,13}$ In the present study, bacterial keratitis was found to occur more frequently in boys than in girls. Kunimoto et $a l^{1}$ did not identify unequal gender distribution in paediatric microbial keratitis cases, whereas Cruz et $a l^{5}$ have found a male preponderance.

The yield rate for corneal cultures in this study was $73.8 \%$, which was significantly higher than previous reports from East Asia ${ }^{1,6}$ but similar to the North American and South Asia experience. 5,7,14 The prevalence of pathogens causing paediatric bacterial keratitis varies among previous reports. Ormerod et al found that $92 \%$ of infections involved $P$. aeruginosa and/or various streptococcus species; later in childhood the typical adult pattern of infection was more common. Cruz et $a l^{5}$ revealed that $P$. aeruginosa and Staphylococcus aureus were the most common organisms isolated. Similarly to previous studies, ${ }^{1,6}$ in our series, Staphylococcus species and S. pneumoniae were the predominant Gram-positive micro-organisms and P. aeruginosa was the major Gram-negative microorganism associated with bacterial keratitis in children. Geographical and climatic factors may partially explain the different prevalence rate. Notably, the role of S. epidermidis in the pathogenesis of bacterial keratitis is controversial and has not been clearly determined, because of its potential to contaminate an otherwise sterile corneal scraping and its controversial virulence.

In the 59 cases recruited, we did not find Haemophilus influenzae. There were two possible reasons for this 
Table 4 Clinical characteristics of paediatric bacterial keratitis cases and univariate analysis

\begin{tabular}{|c|c|c|c|c|}
\hline Variables & Total & $\begin{array}{l}\text { Visual } \\
\text { impairment } \\
\text { group }\end{array}$ & $\begin{array}{l}\text { Non visual } \\
\text { impairment } \\
\text { group }\end{array}$ & P-value \\
\hline Age (years) ${ }^{\mathrm{a}}$ & $6.6 \pm 4.4$ & $7.2 \pm 4.2$ & $6.0 \pm 4.8$ & 0.236 \\
\hline Gender $(\mathrm{n})^{\mathrm{b}}$ & & & & 0.286 \\
\hline Male & 37 & 24 & 13 & \\
\hline Female & 22 & 11 & 11 & \\
\hline Bacterial isolates $(\mathrm{n})^{\mathrm{b}}$ & & & & 0.172 \\
\hline Gram-positive infection & 48 & 26 & 22 & \\
\hline Gram-negative infection & 11 & 9 & 2 & \\
\hline Types of antibiotics resistant $(n)^{a}$ & $1.5 \pm 0.8$ & $1.7 \pm 0.8$ & $1.2 \pm 0.6$ & 0.019 \\
\hline Onset time $(\mathrm{n})^{\mathrm{b}}$ & & & & 0.103 \\
\hline 1 month or longer & 23 & 17 & 6 & \\
\hline Shorter than 1 month & 36 & 18 & 18 & \\
\hline Ocular surface disease $(\mathrm{n})^{\mathrm{b}}$ & & & & 0.029 \\
\hline Yes & 23 & 18 & 5 & \\
\hline No & 36 & 17 & 19 & \\
\hline Ocular surgery $(\mathrm{n})^{\mathrm{b}}$ & & & & 0.172 \\
\hline Yes & 11 & 9 & 2 & \\
\hline No & 48 & 26 & 22 & \\
\hline Ocular trauma $(\mathrm{n})^{\mathrm{b}}$ & & & & 0.498 \\
\hline Yes & 11 & 8 & 3 & \\
\hline No & 48 & 27 & 21 & \\
\hline
\end{tabular}

${ }^{\text {a }}$ Mann-Whitney test was used.

${ }^{\mathrm{b}} \chi^{2}$-test and Fisher's exact test was performed.

Table 5 Results of multivariate logistic regression for visual impairment using variables mentioned in Table 3

\begin{tabular}{|c|c|c|c|c|}
\hline \multirow[t]{2}{*}{ Variables } & \multirow[t]{2}{*}{ P-value } & \multirow[t]{2}{*}{ Odds ratio } & \multicolumn{2}{|c|}{$95 \%$ CI for odds ratio } \\
\hline & & & Lower & Upper \\
\hline Bacterial isolates (reference, gram-positive infection) & 0.043 & 7.626 & 1.063 & 54.719 \\
\hline Types of antibiotics resistant & 0.040 & 0.385 & 0.155 & 0.956 \\
\hline Onset time (reference, 1 month or longer) & 0.048 & 0.251 & 0.064 & 0.987 \\
\hline Ocular surface disease (reference, yes) & 0.179 & 0.383 & 0.095 & 1.552 \\
\hline Ocular surgery (reference, yes) & 0.258 & 0.291 & 0.034 & 2.472 \\
\hline
\end{tabular}

Abbreviation: $\mathrm{CI}$, confidence interval.

phenomenon. First, $H$. influenzae is a frequently isolated pathogen in the paediatric population in ocular surface infection, but mostly in acute bacterial conjunctivitis. The incidence of $H$. influenzae in paediatric keratitis was very low. Hsiao et al ${ }^{8}$ reported that 2 of 78 children with microbial keratitis in Taiwan were found to have $H$. influenzae infection. Keay et al ${ }^{15}$ revealed that only one case was found positive for this bacteria in 291 microbial keratitis patients. ${ }^{15}$ Also, according to the Preferred Practice Pattern published by American Academy
Ophthalmology, the incidence of $H$. influenzae in common causes of bacterial keratitis in the USA was only $2.5 \%$. Second, the present study was performed in a tertiary eye care unit in Shanghai. We did not encounter the cases receiving effective treatment in primary or secondary hospital and therefore having no need for further referral. Caution should be taken in the interpretation of the results of this study.

To date, there is little information available about in vitro susceptibility patterns to antibiotics of paediatric 
bacterial keratitis cases. Our study showed a better efficacy of fluoroquinolones than aminoglycosides in the treatment of bacterial keratitis, though both had acceptable susceptibility rates. Nowadays, the use of fluoroquinolones has gained popularity as an effective monotherapy for these patients. ${ }^{16-20}$ These agents provide coverage against most Gram-negative and Gram-positive bacteria, good ocular penetration, low toxicity, safety, and commercial availability. ${ }^{21}$ Hence, even though several cases of fluoroquinolone resistance have been published, ${ }^{18,22,23}$ our results show that, based on the susceptibility results for this geographic region, quinolones are still a good choice for paediatric bacterial keratitis in the Eastern China area, just as the susceptibility test in the current study showed. In addition, the first-generation cephalosporin, cefazolin, had a low level of antibacterial efficacy. However, the third-generation cephalosporins, cefepime and ceftazidime, had high activity against microorganisms involved in paediatric bacterial keratitis. Ceftazidime may be used as a fortified antibiotic in treating bacterial keratitis.

In our study, 24 eyes (40.7\%) were considered to be visually impaired. Previous studies showed that 11.8-39.3\% of childhood microbial keratitis, not just bacterial infection, had a visual outcome of worse than $6 / 60.2,7,8,24$ Variations in the reported visual impairment rate may be because of the inclusion of patients with different severity and different pathogen. Relationships between the presence of visual impairment and clinical characteristics of paediatric patients were also explored in the present study, and Gram-negative bacterial infection and the increasing number of resistant antibiotics were found to be independent risk factors. Previous reports have addressed the risk factors predisposing patients to worse prognosis of bacterial keratitis. In the last century, infection caused by $P$. aeruginosa was most likely to result in a poor outcome. ${ }^{15}$ Ten years later, Miedziak et $a l^{25}$ reported that older age, delay in referral to the corneal specialist, topical steroid treatment, past ocular surgery, poor vision at presentation, large size and central location of the ulcer were risk factors for poor outcome of microbial keratitis leading to penetrating keratoplasty. In 2003, Bourcier et $a l^{26}$ revealed that 'very poor' visual outcome was significantly correlated with a history of ocular surface disease or systemic disease, diffuse infiltrate localised at the central or inferior cornea, severe anterior chamber inflammation, and depth of the infiltrate. In their series, there was no correlation between visual outcome and contact lens wear, history of corneal trauma or surgery, number of localisations, and type of bacteria. Recently, though, Keay et al 27 identified that ocular trauma and contact lens wear are the major predisposing factors for microbial keratitis in adolescents and adults ranging from 15 to 64 years in age, and vision loss was proved to be only associated with clinical severity.

Interestingly, onset time proved to have significant correlation with visual impairment by multivariate logistic regression analysis (Table 5), which was different from univariate analysis (Table 4). In previous studies, longer delay between the onset of the symptoms and the first examination is thought to be an important indicator of prognosis. ${ }^{26}$ However, logistic regression analysis using onset time and other variables, as shown in Supplementary Table 1, revealed that this phenomenon might be attributed to the bias induced by bacterial isolates infection. The disparity between previous studies and ours may have several reasons. First, previous studies were carried out in all ages or adults, while our cases were all children. Second, the patients enroled may have different clinical severity, which would bias the results. Third, different statistical methods used may be another explanation. The simplicity of the univariate analysis has restricted its use because several factors can affect visual outcomes. Multivariate analysis can describe and be used for inference on a set of data even when several variables are involved, so its conclusion is more persuasive.

Several limitations of the present study should be noted. First, it is a retrospective study, and information of risk factors was only available when documented in the medical record. Some individuals may have additional risk factors that were not reported in their clinical record, such as the severity of corneal ulcers, including size, location, depth, and reaction. Second, similarly to previous studies, the present study was performed in a tertiary eye care unit in Shanghai, which may result in a potential selection bias. Third, in vitro susceptibilities were based on serum concentrations that may not be applicable to topically administered antibiotics, but these susceptibility patterns were still useful for guiding clinical judgment in antibiotic choice. Another limitation is that the presence of visual impairment was difficult to confirm in underage children. We have no alternative but to consider them as being visually impaired by the diagnosis of corneal leukoma.

In summary, among paediatric bacterial keratitis cases in our unit, S. epidermidis, S. pneumoniae, and P. aeruginosa were the most commonly isolated pathogens. The presence of visual impairment in paediatric patients was significantly associated with Gram-negative infection and the increasing number of resistant antibiotics. These findings may be important because they suggest that results of corneal culture and in vitro susceptibility are useful for indicating the prognosis of paediatric bacterial keratitis cases. 


\section{Summary}

What was known before

- Only a few studies from the United States, India, and Taiwan have reported the characteristics of paediatric bacterial keratitis in children.

- To date, there is little information available about in vitro susceptibility patterns to antibiotics of paediatric bacterial keratitis cases.

- Relationships between presence of visual impairment and clinical characteristics of paediatric patients were explored by univariate analysis.

\section{What this study adds}

- This study provided the microbiological profile, in vitro antibiotic susceptibility, and visual outcomes of paediatric microbial keratitis in China for the first time.

- S. epidermidis was the most common bacterial keratitis isolate in children in Shanghai. The fluoroquinolones and aminoglycosides remained good choices for treating these patients.

- By multivariate logistic regression analysis, we found that Gram-negative bacterial infection and increasing number of resistant antibiotics may predict worse visual outcome.

\section{Conflict of interest}

The authors declare no conflict of interest.

\section{Acknowledgements}

This work was supported by grants from the Key Clinic Medicine Research Program, the Ministry of Health, China (2010-2012); Doctoral Fund, the Ministry of Education, China; National Science and Technology Research Program, the Ministry of Science and Technology, China (2012BAI08B01); National Natural Science Foundation of China (81170817, 81200658); Scientific Research Program, Science and Technology Commission of Shanghai Municipality, Shanghai (11231200602, 11DZ2260900). The sponsor or funding organisation had no role in the design or conduct of this research. The authors thank Dr Junzhi He for the assistance in statistical analysis.

\section{References}

1 Ormerod LD, Murphree AL, Gomez DS, Schanzlin DJ, Smith RE. Microbial keratitis in children. Ophthalmology 1986; 93: 449-455.

2 Kunimoto DY, Sharma S, Reddy MK, Gopinathan U, Jyothi J, Miller D et al. Microbial keratitis in children. Ophthalmology 1998; 105: 252-257.

3 Garg P, Sharma S, Rao GN. Ciprofloxacin-resistant Pseudomonas keratitis. Ophthalmology 1999; 106: 1319-1323.

4 Schwartz GS, Holland EJ. Oral acyclovir for the management of herpes simplex virus keratitis in children. Ophthalmology 2000; 107: 278-282.
5 Cruz OA, Sabir SM, Capo H, Alfonso EC. Microbial keratitis in childhood. Ophthalmology 1993; 100: 192-196.

6 Clinch TE, Plamon FE, Robinson MJ, Cohen EJ, Barron BA, Laibson PR. Microbial keratitis in children. Am J Ophthalmol 1994; 117: 65-71.

7 Vajpayee RB, Ray M, Panda A, Sharma N, Taylor HR, Murthy GV et al. Risk factors for pediatric presumed microbial keratitis: a case-control study. Cornea 1999; 18: 565-569.

8 Hsiao CH, Yeung L, Ma DH, Chen YF, Lin HC, Tan HY et al. Pediatric microbial keratitis in Taiwanese children: a review of hospital cases. Arch Ophthalmol 2007; 125: 603-609.

9 Singh G, Palanisamy M, Madhavan B, Rajaraman R, Narendran K, Kour A et al. Multivariate analysis of childhood microbial keratitis in South India. Ann Acad Med Singapore 2006; 35: 185-189.

10 Wong VW, Lai TY, Chi SC, Lam DS. Pediatric ocular surface infections: a 5-year review of demographics, clinical features, risk factors, microbiological results, and treatment. Cornea 2011; 30: 995-1002.

11 Musch DC, Sugar A, Meyer RF. Demographic and predisposing factors in corneal ulceration. Arch Ophthalmol 1983; 101: 1545-1548.

12 Upadhyay MP, Karmacharya PC, Koirala S, Tuladhar NR, Bryan LE, Smolin G et al. Epidemiologic characteristics, predisposing factors, and etiologic diagnosis of corneal ulceration in Nepal. Am J Ophthalmol 1991; 111: 92-99.

13 Stretton S, Gopinathan U, Willcox MD. Corneal ulceration in pediatric patients: a brief overview of progress in topical treatment. Paediatr Drugs 2002; 4: 95-110.

14 Jhanji V, Naithani P, Lamoureux E, Agarwal T, Sharma N, Vajpayee RB. Immunization and nutritional profile of cases with atraumatic microbial keratitis in preschool age group. Am J Ophthalmol 2011; 151: 1035-1040.

15 Keay L, Edwards K, Naduvilath T, Taylor HR, Snibson GR, Forde $\mathrm{K}$ et al. Microbial keratitis predisposing factors and morbidity. Ophthalmology 2006; 113: 109-116.

16 Kunimoto DY, Sharma S, Garg P, Rao GN. In vitro susceptibility of bacterial keratitis pathogens to ciprofloxacin. Emerging resistance. Ophthalmology 1999; 106: 80-85.

17 Bower KS, Kowalski RP, Gordon YJ. Fluoroquinolones in the treatment of bacterial keratitis. Am J Ophthalmol 1996; 121: 712-715.

18 Neu HC. Microbiologic aspects of fluoroquinolones. Am J Ophthalmol 1991; 112: 15-24.

19 Chalita MR, Höfling-Lima AL, Paranhos A, Schor P, Belfort $\mathrm{R}$. Shifting trends in in vitro antibiotic susceptibilities for common ocular isolates during a period of 15 years. Am J Ophthalmol 2004; 137: 43-51.

20 Goldstein MH, Kowalski RP, Gordon YJ. Emerging fluoroquinolone resistance in bacterial keratitis: a 5-year review. Ophthalmology 1999; 106: 1313-1318.

21 Zhang C, Liang Y, Deng S, Wang Z, Li R, Sun X. Distribution of bacterial keratitis and emerging resistance to antibiotics in China from 2001 to 2004. Clin Ophthalmol 2008; 2: 575-579.

22 Ta CN, Chang RT, Singh K, Egbert PR, Shriver EM, Blumenkranz MS et al. Antibiotic resistance patterns of ocular bacterial flora: a prospective study of patients undergoing anterior segment surgery. Ophthalmology 2003; 110: 1946-1951.

23 Chung JL, Seo KY, Yong DE, Mah FS, Kim TI, Kim EK et al. Antibiotic susceptibility of conjunctival bacterial isolates 
from refractive surgery patients. Ophthalmology 2009; 116: 1067-1074.

24 Forster RK. Conrad Berens Lecture. The management of infectious keratitis as we approach the 21st century. CLAO J 1998; 24: 175-180.

25 Miedziak AI, Miller MR, Rapuano CJ, Laibson PR, Cohen EJ. Risk factors in microbial keratitis leading to penetrating keratoplasty. Ophthalmology 1999; 106: 1166-1170.
26 Coster DJ, Badenoch PR. Host, microbial, and pharmacological factors affecting the outcome of suppurative keratitis. Br J Ophthalmol 1987; 71: 96-101.

27 Parmar P, Salman A, Kalavathy CM, Kaliamurthy J, Thomas PA, Jesudasan CA. Microbial keratitis at extremes of age. Cornea 2006; 25: 153-158.

Supplementary Information accompanies the paper on Eye website (http://www.nature.com/eye) 